\title{
PENGEMBANGAN FILM ANIMASI 3 DIMENSI PERAN KAPTEN IDA BAGUS PUTU JAPA DALAM SERANGAN UMUM KOTA DENPASAR
}

\author{
Adhinta Candra Rima Pratama1), I Gede Mahendra Darmawiguna 2), I Gede Bendesa Subawa ${ }^{3)}$ \\ Program Studi Pendidikan Teknik Informatika \\ Jurusan Teknik Informatika \\ Fakultas Teknik dan Kejuruan \\ Universitas Pendidikan Ganesha
}

E-mail:pratamac2@gmail.com ${ }^{1)}$, mahendra.darmawiguna@undiksha.ac.id²), gdbendesa@gmail.com ${ }^{3)}$

\begin{abstract}
Abstrak- Sejarah perjuangan para pahlawan seringkali kurang diketahui oleh masyarakat khususnya mengenai sejarah perjuangan pahlawan Kapten Ida Bagus Putu Japa. Hal ini dikarenakan kurangnya sumber informasi tentang cerita pendorong perlawanan. Saat ini, yang diketahui oleh masyarakat hanya Patung Pahlawan Kapten Anumerta Ida Bagus Putu Japa di bundaran Niti Mandala Renon, Denpasar dan nilai - nilai kepahlawan Kapten Ida Bagus Putu Japa juga diabadikan dan disimpan dengan dibuatkan diorama yang terdapat di Museum Bajra Sandhi. Dengan perkembangan teknologi yang sangat pesat, teknologi bermanfaat untuk menyebarkan atau mensosialisasikan informasi kepada khalayak ramai. Penelitian ini bertujuan untuk pengembangan film animasi 3 dimensi peran Kapten Ida Bagus Putu Japa dalam serangan umum kota Denpasar. Sehingga dengan adanya film animasi ini, diharapkan masyarakat lebih mengetahui serta memahami bagaimana perjuangan Kapten Ida Bagus Putu Japa dalam mempertahankan kota Denpasar. Metode penelitian yang digunakan dalam penelitian ini yaitu metode Multimedia Development Life Cycle, yang memiliki 6 tahapan yaitu concept, design, material collecting, assembly, testing, dan distribution. . Berdasarkan hasil dari data pengujian pada uji ahli isi mendapatkan kriteria "Sangat Valid" dengan validitas Aiken sebesar 0,95. Pada uji ahli media mendapatkan kriteria "Sangat Valid" dengan validitas Aiken sebesar 0,96. Pada uji respon pengguna mendapatkan kriteria "Baik" dengan indeks validitas nilai $87 \%$ Sehingga Film Animasi 3 Dimensi ini layak digunakan media sosialisasi dan edukasi kepada masyarakat Kota Denpasar.
\end{abstract}

Kata-kata Kunci: Pahlawan, Riwayat Hidup Kapten Ida Bagus Putu Japa, Museum Bajra Sandhi

\footnotetext{
Abstract- The history of the hero's struggle is often not well known by the public, especially regarding the history of the hero's struggle, Captain Ida Bagus Putu Japa. This is due to the lack of sources of information about the stories of the drivers of resistance. Currently, what is known to the public is the Statue of Hero of the Posthumous Captain Ida Bagus Putu Japa at the Niti Mandala Renon roundabout, Denpasar and the heroic values of Captain Ida Bagus Putu Japa are also enshrined and stored by making a diorama in the Bajra Sandhi Museum. With the rapid development
}

of technology, technology is useful for disseminating or disseminating information to the general public. This study aims to develop a 3-dimensional animated film of the role of Captain Ida Bagus Putu Japa in the general attack of Denpasar city. So that with this animated film, it is hoped that the public will know and understand how the struggle of Captain Ida Bagus Putu Japa in defending the city of Denpasar. The research method used in this study is the Multimedia Development Life Cycle method, which has 6 stages, namely concept, design, material collecting, assembly, testing, and distribution. . Based on the results of the test data on the content expert test, the criteria are "Very Valid" with Aiken's validity of 0.95. In the media expert test, the criteria are "Very Valid" with Aiken's validity of 0.96. In the user response test the criteria are "Good" with a validity index of $87 \%$ so that this $3 D$ animated film is suitable for socialization and education media to the people of Denpasar City.

Keywords: Heroes, Biography of Captain Ida Bagus Putu Japa, Bajra Sandhi Museum

\section{PENDAHULUAN}

Bangsa Indonesia merupakan sekelompok masyarakat yang bersatu atau dipersatukan karena adanya persamaan sejarah dan nasib dimasa lampau, serta memiliki tujuan dan cita - cita yang sama dalam membangun Bhineka Tunggal Ika. Bangsa Indonesia juga bisa diistilahkan sebagai suatu kelompok manusia yang memiliki identitas, bahasa, agama, budaya, idelogi, wilayah, serta sejarah.

Terkait dengan sejarah, tentu saja dalam "Kemerdekaan" Indonesia telah meninggalkan bekas perjalanan sejarah perjuangan rakyat sebelum negara ini merdeka. Indonesia pernah merasakan bagaimana kejamnya penjajahan yang dilakukan oleh beberapa negara asing, salah satunya adalah Belanda. Hampir seluruh daerah di Nusantara berusaha diambil alih oleh mereka. Salah satunya adalah daerah bagian dari Kepulauan Nusa Tenggara, yaitu Bali. 
Bali merupakan salah satu provinsi yang dijajah oleh Belanda, tepatnya pada masa lampau pada tahun 1946, Belanda secara gencar ingin menaklukkan Bali. Belanda memiliki dendam terhadap Bali, karena Bali dianggap mengganggu perdagangan saat Belanda masuk ke Indonesia melalui perairan dan penolakan Bali untuk menerima monopoli yang ditawarkan Batavia. Semenjak tentara NICA di Bali, pasukan RI menggunakan berbagai macam sistem gerilya untuk menghentikan tentara NICA (Belanda). Hingga pada akhirnya, Bali dibawah pimpinan tokoh pejuang "Ida Bagus Putu Japa" dan tokoh serta anggota pasukan lainnya melakukan serangan umum kota Denpasar terhadap Belanda dengan Basis penyerangan para gerilya adalah Tangsi Kayumas (Pusat pemerintahan NICA). Dalam pertempuran itu, Kapten Ida Bagus Putu Japa gugur.

Sejarah yang dilakukan oleh pahlawan sangat penting untuk menumbuhkan sikap nasionalisme dan cinta tanah air. Informasi tentang sejarah dapat memberikan informasi kepada masyarakat masa kini mengenai keberhasilan dan kegagalan bangsa dalam menjawab segala tantangan yang dihadapi. Fungsi dari sejarah adalah untuk mengenal siapa jati diri bangsa. Sejarah perjuangan pahlawan harus kita hormati untuk membentuk karakter diri bangsa seperti mengembangkan semangat kebangsaan[4]. Dengan adanya semangat pahlawan, masyarakat menjadi semangat dalam bertindak sesuai dengan pahlawan pada masa lampau. Pahlawan yang dibahas salah satunya adalah Kapten Ida Bagus Putu Japa. Untuk mengenang nilai kepahlawan Kapten Ida Bagus Putu Japa, tentu saja masyarakat juga perlu mengetahui sejarah serta perjuangan yang dilakukan oleh Kapten Ida Bagus Putu Japa. Masyarakat perlu memahami perjalanan sejarah yang terjadi pada masa lalu, karena pada dasarnya kehidupan masa kini tidak akan terlepas dari kelamnya kehidupan masa lalu. Sehingga sejarah perlu kita pahami supaya masyarakat bertindak secara bijak dimasa yang akan datang.

Pada kenyataannya, berdasarkan hasil obeservasi yang telah dilakukan atas bukti informasi tentang nilai kepahlawanan Kapten Ida Bagus Putu Japa masih sangat minim. Salah satu penyebabnya informasi lebih lanjut tentang kepahlawanan Kapten Ida Bagus Putu Japa adalah kurangnya sumber informasi tentang cerita pendorong perlawanan membuat tokoh pahlawan Kapten Ida Bagus Putu Japa kurang dikenal masyarakat. Bahkan tidak sedikit masyarakat yang belum mengetahui perjuangan Kapten Ida Bagus Putu Japa. Kurangnya Pengetahuan masyarakat tentang Kapten Ida Bagus Putu Japa dapat dibaca dari angket yang didistribusikan dimasyarakat. Jika dilihat dari angket yang telah didistribusikan di kalangan masyarakat, menunjuk bahwa sebanyak $27,0 \%$ masyarakat mengetahui sejarah tokoh daerah Kapten Ida Bagus Putu Japa dalam mempertahankan Serangan Umum Kota Denpasar dan 73,0\% masyarakat tidak mengetahui sejarah tokoh daerah Kapten Ida Bagus Putu Japa dalam Serangan Umum Kota Denpasar
Saat ini, yang diketahui oleh masyarakat hanya Patung Pahlawan Kapten Anumerta Ida Bagus Putu Japa di bundaran Niti Mandala Renon, Denpasar, sebagai bentuk wujud penghormatan yang diresmikan tanggal 20 November 1987. Tempat itu dipilih karena tempat itu lah yang menjadi saksi, nilai - nilai kepahlawan Kapten Ida Bagus Putu Japa juga diabadikan dan disimpan dengan dibuatkan diorama yang terdapat di Museum Bajra Sandhi. Masyarakat luas hanya mengetahui patung tersebut adalah patung Kapten Ida Bagus Putu Japa, tetapi masyarakat tidak mengetahui sejarah perjuangan pahlawan tersebut.

Masyarakat saat ini perlu disosialisasikan terkait sejarah Kapten Ida Bagus Putu Japa. Salah satu caranya adalah pemanfaatan teknologi. Teknologi yang berkembangnya sangat pesat, dapat dimanfaatkan dalam segala bidang, salah satunya adalah untuk menyebarkan atau mensosialisasikan informasi kepada khalayak ramai. Pemanfaatan teknologi ini yang bisa dilakukan dengan membuat film animasi yang menceritakan sejarah dan latar belakang gugurnya Kapten Ida Bagus Putu Japa. Jenis Film Animasi yang dipilih adalah Film Animasi 3 Dimensi. Penelitian ini menggunakan Film Animasi 3 Dimensi untuk mensosialisasikan nilai Kepahlawanan Kapten Ida Bagus Putu Japa.Berdasarkan dari beberapa penelitian yang terkait maka penulis tertarik untuk mengangkat sejarah dan latar belakang gugurnya Kapten Ida Bagus Putu Japa yang dikemas dalam sebuah Film Animasi 3 Dimensi. Adapun Film Animasi yang akan dikembangkan berjudul : “ Pengembangan Film Animasi 3 Dimensi Peran Kapten Ida Bagus Putu japa dalam Serangan Umum Kota Denpasar".

\section{KAJIAN PUSTAKA DAN TEORI}

\section{A. Profil Kapten Ida Bagus Putu Japa (Gatot Kaca Geriya Bengkel)}

Berdasarkan Buku Inventaris Peristiwa dan Tokoh Sejarah (Wirawan, 2018) pada halaman 324 menjabarkan bahwa Kapten Ida Bagus Putu Japa merupakan Pahlawan yang lahir pada tanggal 3 April 1925 asal dewata ini adalah putra dari Keluarga Brahmana Griya Bengkel, yang artinya beliau lahir ditengah-tengah keluarga shaleh. Ayahnya bernama Ida Bagus Rai (Ida Pedanda Gede Telaga) dan ibunya bernama Gus Istri Rai ( Ida Pedanda Istri Telaga ).Beliau adalah kakak dari tiga orang adiknya yakni Prof. DR. Ida Bagus Made Mantra, Ida Ayu Agung dan Ida Ayu Okawati.

Riwayat pendidikan beliau diantaranya Holland Indlandsche School di jaman Belanda ( setingkat sekolah dasar ) dan Meer Utgebreid Lager Onderwijs di daerah Malang ( setingkat sekolah menengah pertama ) akan tetapi, disekolah ini beliau tidak sampai tamat dikarenakan bala tentara Jepang yang berhasil mendarat di Republik Indonesia pada saat perang dunia 2 dan beliau berkeinginan untuk mengusir penjajah, oleh karena itu beliau kembali ke Denpasar[9]. 
e-ISSN: 2685-7006 |p-ISSN: $2252-9063$

Kumpulan Artikel Mahasiswa Pendidikan Teknik Informatika

(KARMAPATI)

Volume 10, Nomor 3,Tahun 2021

\section{B. Film}

Berdasarkan Undang-Undang No. 8 Tahun 1992 tentang Perfilman, film adalah karya cipta seni dan budaya yang merupakan media komunikasi massa pandang-dengar yang dibuat berdasarkan asas sinematografi dengan direkam pada pita seluloid, pita video, piringan video, dan/atau bahan hasil penemuan teknologi lainnya dalam segala bentuk, jenis, dan ukuran melalui proses kimiawi, proses elektronik, atau proses lainnya, dengan atau tanpa suara, yang dapat dipertunjukkan atau ditayangkan dengan sistem proyeksi mekanik, eletronik, dan lainnya.

\section{Animasi}

Menurut Munir (2013:340) "animasi berasal dari bahasa inggris, animation dari kata to anime yang berarti "menghidupkan". Animasi merupakan gambar tetap (still image) yang disusun secara berurutan dan direkam dengan menggunakan kamera".

Beberapa jenis - jenis animasi yang sering digunakan dan diproduksi :

1. Animasi StopMotion

2. Animasi 2D

3. Animasi 3D

4. Animasi Tanah Liat (Clay Animation)

5. Animasi Jepang (Anime)

6. Animasi GIF

\section{Animasi 3 Dimensi (3D Animation)}

Animasi adalah membuat presentasi statis menjadi hidup. Animasi sebenarnya merupakan sebuah objek yang dapat bergerak keluar/masuk layar dan dengan animasi, serangkaian gambar dapat diubah secara lambat atau cepat, sehingga tampak berpadu ke dalam visual gerak dan dapat juga digabungkan dengan suara (Vaughan, 2004). Animasi 3 Dimensi dibagi beberapa tahap proses yaitu :

$\begin{array}{ll}a . & \text { Modeling } \\ \text { b. } & \text { Lighting } \\ c . & \text { Texturing } \\ \text { d. } & \text { Animation } \\ \text { e. } & \text { Rendering }\end{array}$

\section{E. Perangkat Lunak}

Perangkat lunak yang akan digunakan peneliti dalam membuat film Animasi 3 Dimensi sebagai berikut :

1. $\quad$ Blender versi 2.79

2. $\quad$ Iclone versi 7.7

3. Sony Vegas Pro

4. Adobe Photoshop CC

\section{F. Sinopsis}

Sinopsis adalah tulisan yang memuat latar belakang proses penciptaan suatu karya seni tari, ide (gagasan awal), gerak, dan bentuk tari yang dipilih sebagai media ungkapan estetis atau idenya (Margono, Sumardi, Murtono: 2007),

\section{G. Storyboard}

Storyboard ialah suatu gambaran yang akan disusun secara berurut sesuai alur naskah cerita. Storyboard dapat dikatakan juga visual script yang akan dijadikan outline dari sebuah proyek, ditampilkan shot by shot yang biasa disebut dengan istilah scene. (Nur, 2005)[5].

\section{METODE PENELITIAN}

\section{A. Jenis Penelitian}

Penelitian ini memiliki tujuan untuk mengembangkan film animasi 3 dimensi. Berdasarkan dari tujuan tersebut, maka penelitian menggunakan metode Multimedia Development Life Cycle versi Luther - Sutopo agar pengembangan dari film animasi 3 dimensi dapat memenuhi standar kuliatas. Menurut Luther dalam Iwan Binanto (2010:259), metode pengembangan multimedia terdiri dari enam tahap, yaitu concept, design, material collecting, assembly, testing, dan distribution. Penelitian ini, penulis sampai dengan tahap pengembangan Film Peran Kapten Ida Bagus Putu Japa dalam Serangan Umum kota Denpasar. Penelitian ini bertujuan untuk mengembangkan sebuah Film Animasi 3 Dimensi Peran Kapten Ida Bagus Putu Japa dalam Serangan Umum kota Denpasar.

\section{B. Metode Penelitian}

Model pengembangan yang digunakan dalam penelitian ini yaitu model Multimedia Development Life Cycle versi Luther - Sutopo. Menurut Luther dalam Iwan Binanto (2010:259), model pengembangan multimedia terdiri dari enam tahap, yaitu concept, design, material collecting, assembly, testing, dan distribution. Penelitian ini hanya sampai dengan pengembangan, Film Animasi 3 Dimensi Peran Kapten Ida Bagus Putu Japa dalam Serangan umum kota Denpasar. Berikut gambaran tahapan model Multimedia Development Life Cycle versi Luther Sutopo[2] :

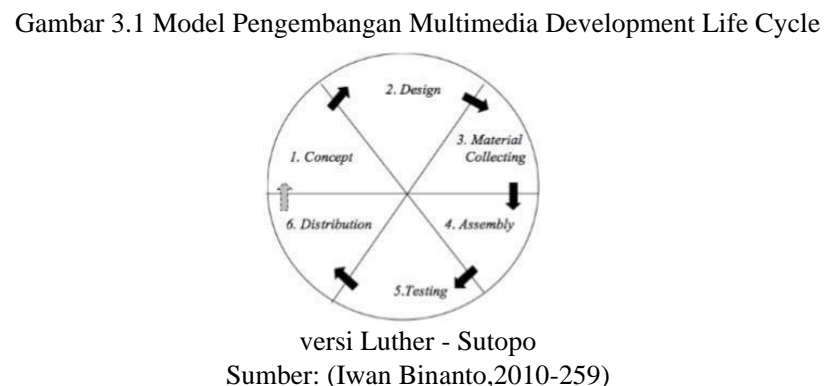

Dijabarkan beberapa tahapan dalam model Multimedia Development Life Cycle versi Luther - Sutopo adalah sebagai beikut :

\section{Concept (Konsep)}

Tahap concept merupakan tahapan untuk 
menentukan tujuan dan siapa yang akan menggunakan. Rincian concept pada penelitian ini terdapat pada tabel 3.1

Tabel 3.1 Concept

\begin{tabular}{|c|c|}
\hline Konsep & Deskripsi \\
\hline Judul & $\begin{array}{l}\text { Film Animasi } 3 \text { Dimensi peran Kapten Ida Bagus Putu Japa } \\
\text { dalam Serangan Umum kota Denpasar }\end{array}$ \\
\hline Jenis & Media Sosisalisasi \\
\hline Tujuan & $\begin{array}{l}\text { Tujuan dari penelitian ini untuk memberikan informasi terkait } \\
\text { perjuangan atau peran Kapten Ida Bagus Putu Japa dalam } \\
\text { Serangan Umum kota Denpasar serta sosisalisasi } \\
\text { masyarakat kota Denpasar }\end{array}$ \\
\hline Sasaran & $\begin{array}{l}\text { Kalangan Masyarakat Kota Denpasar pada Usia } 10 \text { sampai } 20 \\
\text { Tahun }\end{array}$ \\
\hline Audio & $\begin{array}{l}\text { Audio dalam Pengembangan Film Animasi } 3 \text { Dimensi Peran } \\
\text { Kapten Ida Bagus Putu Japa berasal dari beberapa sumber }\end{array}$ \\
\hline $\begin{array}{l}\text { Perangkat } \\
\text { lunak }\end{array}$ & Blender, Iclone versi 7.7, Sony Vegas, Adobe Photoshop \\
\hline Output & $\begin{array}{l}\text { Hasil akhir dari Pengembangan Film Animasi } 3 \text { Dimensi Peran } \\
\text { Kapten Ida Bagus Putu Japa dalam Serangan Umum kota } \\
\text { Denpasar berupa film yang berformat mp4 dengan media } \\
\text { penyimpanan CD dan Digitalisasi yang akan diberikan kepada } \\
\text { Legiun Veteran Republik Indonesia Provinsi Bali }\end{array}$ \\
\hline
\end{tabular}

\section{Design}

Pada tahapan ini dimulai dengan merancang analisis SWOT ,Ide cerita, sinopsis, pembuatan karakter, storyboard, perangkat keras dan perangkat lunak yang dipakai dalam pembuatan film animasi 3 dimensi. Hal tersebut bertujuan agar pembuatan film animasi 3 dimensi lebih terarah dan tertata. Adapaun beberapa tahap yang di lakukan dalam design (perancangan) meliputi :

\section{Analisis SWOT}

Analisis SWOT diperlukan untuk mengetahui masalah - masalah dalam rangkaian memaksimalkan kegiatan produksi film animasi.

\section{Ide Cerita}

Pada ide cerita merupakan hal mendasar yang digunakan untuk mengembangkan sebuah karya film animasi. Ide cerita dari film animasi 3 dimensi peran Kapten Ida Bagus Putu Japa dalam Serangan umum kota Denpasar yang peneliti melihat banyak nya masyarakat kota Denpasar kurangnya informasi tentang kepahlawanan Kapten Ida Bagus Putu Japa.

\section{Perancangan Karakter \\ Pada tahap perancangan karakter merupakan}

pembuatan desain tokoh yang akan di akan di perankan dalam film animasi 3 dimensi. Hal pertama kali yang akan dilakukan dalam pembuatan karakter ini adalah menyusun atau menentukan bentuk fisik serta penampilan tokoh dalam film animasi 3 dimensi.

\section{Sinopsis}

Sinopsis adalah sebuah ringkasan cerita. Dalam synopsis ini terdapat alur cerita yang akan di buat pada film animasi 3 dimensi. Pembuatan synopsis ini untuk menjaga dan mempertahankan sebuah film animasi 3 dimensi untuk tidak keluar jalur dari cerita.

\section{Storyboard}

Storyboard adalah sebuah sketsa gambar yang akan disusun secara berurut sesuai alur naskah cerita atau synopsis. Adanya storyboard ini akan dijadikan acuan dalam pembuatan tampilan film animasi 3 dimensi.

\section{Material Collecting}

Merupakan tahapan pengumpulan bahan, dalam hal ini yang akan digunakan berupa sebuah teks, gambar, animasi, serta suara. Kebutuhan - kebutuhan aplikasi tersebut dapat diperoleh dengan cara membuat sendiri menggunakan Adobe Photoshop CC, Blender, Iclone, Sony Vegas, Adobe Adobe Primerex Pro CC, selain itu, ada beberapa bahan bersumber dari internet yang selanjutnya diproses menggunakan software.

\section{Assembly}

Pada tahapan ini adalah bagian yang terpenting dalam pembuatan atau kegiatan dalam produksi film animasi 3 dimensi. Dalam tahap ini, film animasi 3 dimensi disesuaikan dengan tahap design. Proses produksi film animasi 3 dimensi membutuhkan alur kerja produksi yang tepat, teratur dan sistematis.

\section{Testing}

Tahap testing (pengujian) merupakan tahapan yang dilakukan setelah penyelesaiaan pembuatan produk dengan melihat apakah standar produk berjalan dengan baik pada perangkat computer manapaun. Apabila terjadi kesalahan dengan produk maka produk akan diperbaharui Jika sudah berjalan dengan baik sesuai rancangan serta tujuan maka proses selanjutnya yaitu penyelesaian dan distribusi. Pada tahap ini terdapat testing (pengujiaan) dibagi menjadi 3 tahap yaitu :

1. Uji ahli isi

Uji ahli isi digunakan untuk mengetahui standar isi dari kesesuaian Film Animasi 3 Dimensi Peran Kapten Ida Bagus Putu Japa dalam Serangan umum kota Denpasar agar sesuai dengan kriteria dan kebutuhan dari 
e-ISSN: 2685-7006 | p-ISSN: 2252-9063

Kumpulan Artikel Mahasiswa Pendidikan Teknik Informatika

(KARMAPATI)

KคRMAPคTI

Volume 10, Nomor 3,Tahun 2021

pengguna

Tabel 3.3 Kisi Kisi Uji Ahli Isi

\section{Uji Ahli Media}

Uji Ahli Media digunakan menjadi acuan dasar agar dapat mengetahui kesesuaian teknis Peran Kapten Ida Bagus Putu Japa dalam Serangan umum kota Denpasar pada pembuatan Film Animasinya, baik itu dalam segi visual maupun audio film animasi 3 dimensi.

Tabel 3.4 Kisi Kisi Uji Ahli Media

\begin{tabular}{|r|r|l|}
\hline \multicolumn{1}{|c|}{$\begin{array}{l}\mathrm{N} \\
\mathrm{o}\end{array}$} & Fokus & \multicolumn{1}{|c|}{ Kisi - kisi } \\
\hline 1 & $\begin{array}{c}\text { Kesesua } \\
\text { ian visual }\end{array}$ & $\begin{array}{l}\text { Adapun pertanyaan pada fokus pertama } \\
\text { meliputi : pergerakan efek karakter latar } \\
\text { pendukung,penempatan logo, pemilihan } \\
\text { jenis font, dan gerakan }\end{array}$ \\
\hline 2 & $\begin{array}{c}\text { Kesesua } \\
\text { ian audio }\end{array}$ & $\begin{array}{l}\text { Adapun pertanyaan pada fokus kedua } \\
\text { meliputi tentang: suara narasi, suara dialog, } \\
\text { logat dan durasi }\end{array}$ \\
\hline
\end{tabular}

Pada Uji Ahli isi dan Uji ahli Media penulis menggunakan indeks Validitas Aiken $\mathrm{V}$, dengan rentang 0 sampai dengan 1. Jika angka $\mathrm{V}$ lebih tinggi (mendekati 1 atau sama dengan 1), nilai validitas item atau butir soal menjadi lebih tinggi dan semakin rendah angka $\mathrm{V}$ (mendekati 0 atau sama dengan 0), nilai validitas suatu item atau butir soal menjadi lebih rendah. Menurut (Aiken, 1980,p.956 dalam Arifin \& Retnawati, 2017) validitas Aiken v memiliki criteria penilaian sebagai berikut:[1]

Tabel 3.5 Kriteria Penilaian Butir

\begin{tabular}{|c|c|}
\hline Koefisien Validitas (v) & Kriteria \\
\hline $0,81-1,00$ & Sangat Valid \\
\hline $0,61-0,80$ & Valid \\
\hline $0,41-0,60$ & Cukup \\
\hline $0,21-0,40$ & Kurang Valid \\
\hline $0,00-0,20$ & Tidak Valid \\
\hline
\end{tabular}

Tabel 3.6 Kriteria Validitas Aiken V

\begin{tabular}{|c|c|}
\hline Koefisien Validitas (v) & Kriteria \\
\hline $0,81-1,00$ & Sangat Valid \\
\hline $0,61-0,80$ & Valid \\
\hline $0,41-0,60$ & Cukup \\
\hline $0,21-0,40$ & Kurang Valid \\
\hline $0,00-0,20$ & Tidak Valid \\
\hline
\end{tabular}

Penilaian Uji Ahli Isi dan Uji Ahli Media menggunakan indeks validitas Aiken v sebagai berikut[7]:

$$
\mathbf{v}=\frac{\sum s}{N(\boldsymbol{c}-\mathbf{1})} \quad \operatorname{dimana} s=r-l o
$$

Keterangan :

$r=$ rating penilai

$l o=$ rating penilai kategori terendah

$c=$ kategori tertinggi

$N=$ jumlah penilai/responden

\section{Uji Respon Pengguna}

Uji Respon Pengguna bertujuan untuk mengetahui kepuaasan dan tanggapan masyarakat terhadap film animasi
3 Dimensi Peran Kapten Ida Bagus Putu Japa. Uji Respon

\begin{tabular}{|c|l|}
\hline No & \multicolumn{1}{|c|}{ Kisi- kisi } \\
\hline 1 & $\begin{array}{l}\text { Adapun pertanyaan meliputi : kesesuaian antara buku sebagai } \\
\text { acuan dengan hasil, kesesuaian antara cerita yang ada, artikel } \\
\text { Dinas Sosial kota Denpasar, perancangan karakter, storyboard } \\
\text { dan musik }\end{array}$ \\
\hline
\end{tabular}

Pengguna dilakukan dengan cara menyebarkan angket ke masyarakat sebagai responden. Uji Respon Pengguna menggunakan Metode yang digunakan dalam pengukuran adalah skala Likert, angket uji dibuat dalam bentuk checklist dengan lima gradasi pilihan, yaitu Sangat Setuju (SS), Setuju (S), Cukup Setuju (CS), Tidak Setuju (TS) dan Sangat Tidak Setuju (STS) [3]. Penilaian dari uji respons penonton dapat Tabel 3.7

Tabel 3.7 Skor Angket Uji Respon Pengguna
\begin{tabular}{|c|c|c|}
\hline Skala Jawaban & $\begin{array}{c}\text { Skor } \\
\text { Positif }\end{array}$ & $\begin{array}{c}\text { Skor } \\
\text { Negatif }\end{array}$ \\
\hline Sangat Setuju (SS) & 5 & 1 \\
\hline Setuju (S) & 4 & 2 \\
\hline Cukup Setuju (CS) & 3 & 3 \\
\hline Tidak Setuju (TS) & 2 & 4 \\
\hline $\begin{array}{c}\text { Sangat Tidak Setuju } \\
\text { (STS) }\end{array}$ & 1 & 5 \\
\hline
\end{tabular}

Penilaian kelayakan pada angket uji menggunakan persentase. Menghitung persentase setiap subyek digunakan rumus (Sugiono, 2011).

$$
p=\frac{f}{n} x 100 \%
$$

$p=$ Persentase

$f=$ Frakuensi dari setiap jawaban angket / jumlah total

$n=$ Jumlah skor ideal

$100=$ Bilangan tetap

Untuk melihat kriteria atau tingkat pencapaian pengembangan film, persentase yang telah diperoleh kemudian ditransformasikan ke dalam kalimat seperti kriteria yang ditunjukkan pada Tabel 3.8

Tabel 3.8 Range Persentase Kelayakan Film

\begin{tabular}{|c|c|c|c|}
\hline NO & Interval & Kualitikasi & Keterangan \\
\hline 1 & $90 \%-100 \%$ & Sangat Baik & Tidak perlu direvisi \\
\hline 2 & $75 \%-89 \%$ & Baik & Tidak perlu direvisi \\
\hline 3 & $65 \%-74 \%$ & Cukup & Direvisi \\
\hline 4 & $55 \%-64 \%$ & Kurang & Direvisi \\
\hline 5 & $0 \%-54 \%$ & Sangat Kurang & Direvisi \\
\hline
\end{tabular}

\section{Distribution}

Tahap ini merupakan proses yang distirbusi dengan menyimpan hasil produk ke dalam media penyimpanan yang berupa Compact Disk (CD) serta dengan Digitalisasi . Setelah itu di distribusikan ke Legiun Veteran Republik Indonesia Provinsi Bali dan sebagai sarana media informasi kepada masyarakat kota denpasar. 
e-ISSN: 2685-7006 | p-ISSN: 2252-9063

Kumpulan Artikel Mahasiswa Pendidikan Teknik I ${ }^{-}$..........

(KA

Volume 10, Nomor 3,;

\section{KดRMAPดTI}

\section{HASIL DAN PEMBAHASAN}

A. Hasil

1. Hasil tahapan concept

Tahapan concept merupakan tahapan paling dasar dalam pembuatan Film Animasi 3 Dimensi Peran Kapten Ida Bagus Putu Japa dalam Serangan Umum Kota Denpasar. Hasil dari tahapan concept ini dapat dilihat pada tabel 4.1

Tabel 4.1 Hasil tahapan concept

\begin{tabular}{|c|c|}
\hline $\begin{array}{l}\text { Tahapan } \\
\text { Concept }\end{array}$ & Deskripsi \\
\hline Judul & $\begin{array}{l}\text { Pengembangan Film Animasi } 3 \text { Dimensi Peran } \\
\text { Kapten Ida Bagus Putu Japa dalam Serangan Umum } \\
\text { Kota Denpasar }\end{array}$ \\
\hline $\begin{array}{l}\text { Software yang } \\
\text { digunakan }\end{array}$ & $\begin{array}{l}\text { Blender, Iclone versi } 7.7 \text {, Sony Vegas, Adobe } \\
\text { Photoshop }\end{array}$ \\
\hline $\begin{array}{l}\text { Pedoman Isi } \\
\text { Cerita }\end{array}$ & $\begin{array}{l}\text { Mengacu pada sumber buku Gempilan Perjuangan } \\
\text { Phisik Pasukan Induk Ngurah Rai karya I Gusti } \\
\text { Ngurah Pindha, Buku Inventaris Peristiwa dan } \\
\text { Tokoh Sejarah Karya A.A Bagus Wirawan, artikel } \\
\text { Dinas Sosial Pemerintah Kota Denpasar, serta hasil } \\
\text { wawancara bapak I Gusti Bagus Saputra yang } \\
\text { merupakan Ketua Legiun Veteran Republik } \\
\text { Indonesia Provinsi Bali dan bapak Ketut Suwerta } \\
\text { yang merupakan Kepala Dinas Sosial Provinsi Bali }\end{array}$ \\
\hline Audio & $\begin{array}{l}\text { Menggunakan rekaman suara dari peneliti dan } \\
\text { beberapa musik yang diambil dari beberapa sumber } \\
\text { dengan format .mp3 ataupun .wav }\end{array}$ \\
\hline Video & Hasil akhir berupa video dengan format .mp4 \\
\hline Output & $\begin{array}{l}\text { Hasil akhir dari Pengembangan Film Animasi } 3 \\
\text { Dimensi Peran Kapten Ida Bagus Putu Japa dalam } \\
\text { Serangan Umum kota Denpasar berupa film yang } \\
\text { berformat mp4 dengan media penyimpanan CD dan } \\
\text { Digitalisasi yang akan diberikan kepada Legiun } \\
\text { Veteran Republik Indonesia Provinsi Bali }\end{array}$ \\
\hline
\end{tabular}

\section{Hasil Tahapan Design}

Hasil tahapan design mencakup beberapa bagian rancangan, diantaranya hasil rancangan karakter, hasil rancangan latar pendukung, hasi rancangan storyboard, hasil rancangan cover CD/DVD, dan hasil rancangan poster Film Animasi 3 Dimensi Peran Kapten Ida Bagus Putu Japa dalam Serangan Umum Kota Denpasar. Berikut merupakan rincian dari setiap proses :

a. Hasil Rancangan Karakter

Berikut rancangan karakter film animasi 3 dimensi Kapten Ida Bagus Putu Japa dalam Serangan Umum Kota Denpasar dilihat pada tabel 4.2

Tabel 4.2 Hasil Rancangan Karakter

\begin{tabular}{|c|c|c|}
\hline NAMA TOKOH & $\begin{array}{c}\text { RANCANGAN } \\
\text { AWAL }\end{array}$ & RANCANGAN 3D \\
\hline $\begin{array}{l}\text { Kapten Ida Bagus Putu } \\
\text { Japa }\end{array}$ & & \\
\hline
\end{tabular}

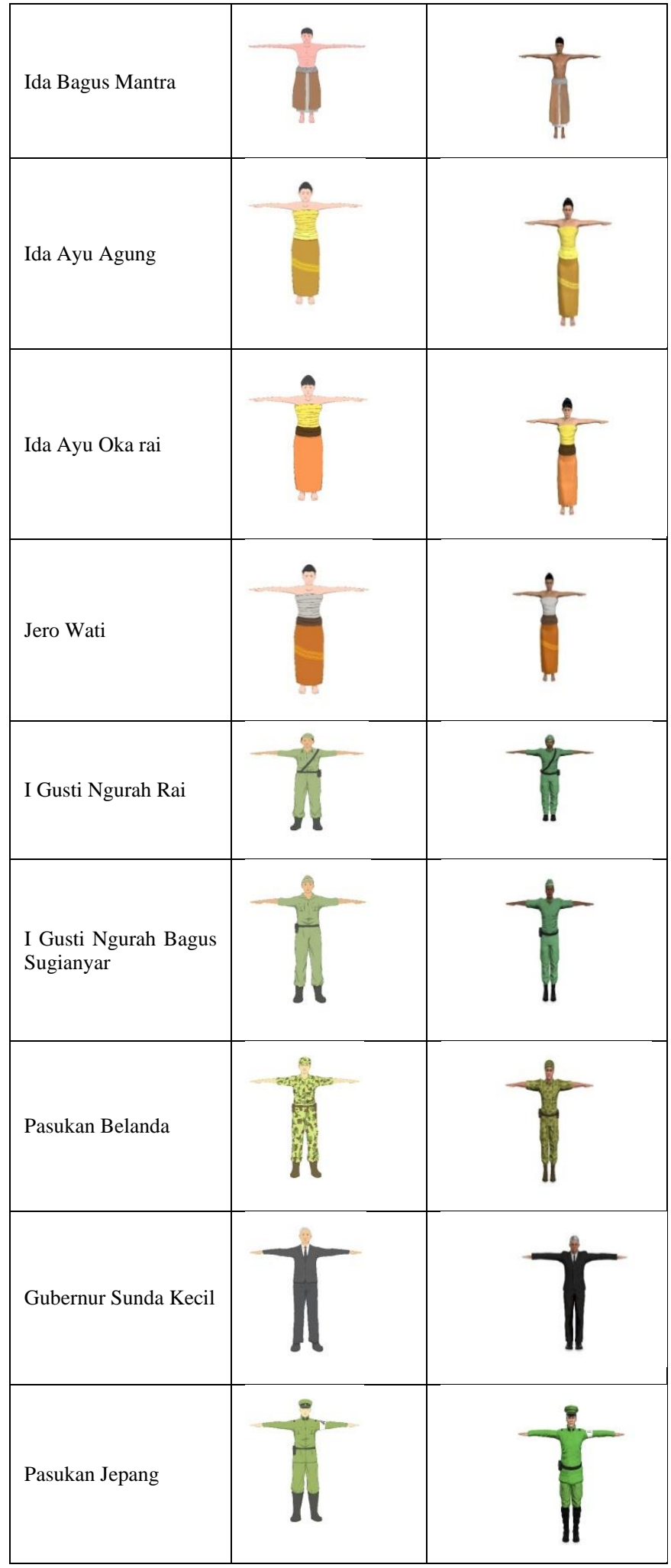


e-ISSN: 2685-7006 | p-ISSN: 2252-9063

Kumpulan Artikel Mahasiswa Pendidikan Teknik Informatika

(KARMAPATI)

KคRMAPคTI

\begin{tabular}{|l|l|l|}
\hline Pasukan Indonesia & (1) \\
\hline
\end{tabular}

b. Hasil Rancangan Latar Pendukung

Pada rancangan latar pendukung pada pengembangan film animasi 3 dimensi Peran Kapten Ida Bagus Putu Japa dalam Serangan Umum Kota Denpasar ini terdapat beberapa gambar latar pendukunh yang akan digunakan sebagai tempat adegan film. Berikut rancangan latar pendukung film animasi 3 dimensi Kapten Ida Bagus Putu Japa dalam Serangan Umum Kota Denpasar dapat dilihat pada tabel 4.3 Tabel 4.3 Hasil Rancangan Latar Pendukung

\begin{tabular}{|l|l|l|l|}
\hline $\begin{array}{l}\text { NAMA } \\
\text { LATAR } \\
\text { PENDU } \\
\text { KUNG }\end{array}$ & GAMBAR AWAL & GAMBAR 3 D \\
\hline Sungai & & & \\
\hline & & & \\
\hline $\begin{array}{l}\text { Tangsi } \\
\text { NICA di } \\
\text { Denpasa } \\
\text { r }\end{array}$ & & & \\
\hline
\end{tabular}

3. Hasil Tahapan Material Collecting

Tahapan Material Collecting merupakan tahapan yang sangat berpengaruh dalam produksi film animasi. Beberapa bahan yang sudah dikumpulkan seperti, sumber yang dapat
Volume 10, Nomor 3,Tahun 2021

dipercaya berupa buku atau hasil wawancara, gambar, animasi, perangkat keras dan perangkat lunak. Setelah itu melakukan pengisian suara untuk membuat suara pada masing - masing karakter ataupun narrator.

4. Hasil Tahapan Assembly

Tahapan Assembly adalah tahapan pembuatan atau produksi film yang telah dirancang sebelumnya.

1. Produksi

Tahapan produksi ialah suatu produksi film yang dibuat sesuai dengan rancangan yang telah disusun sebelumnya. Tahapan produksi sebagai berikut :

\section{a. Modelling}

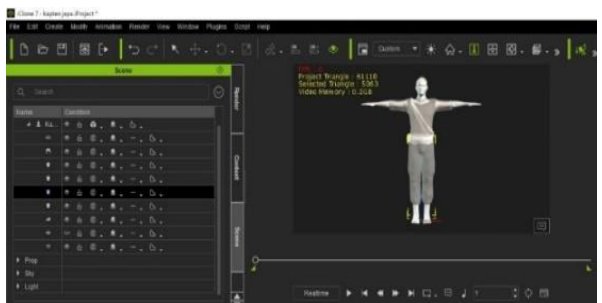

Gambar 4.4 Proses Tahapan Modelling

b. Lighting

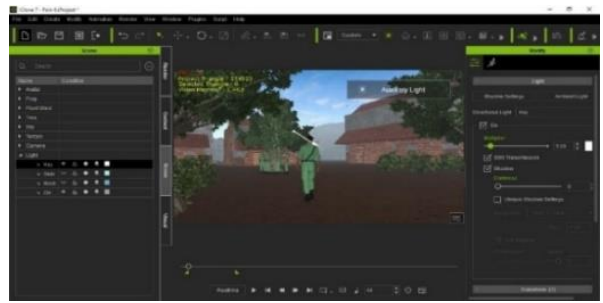

Gambar 4.5 Proses Tahapan Lighting

$c$.

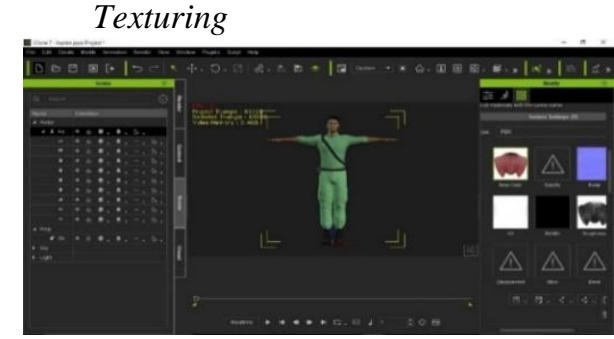

Gambar 4.6 Proses Tahapan Texturing

\section{d. Animation}


e-ISSN: 2685-7006 | p-ISSN: $2252-9063$

Kumpulan Artikel Mahasiswa Pendidikan Teknik Informatika

(KARMAPATI)

KดRMดPคTI

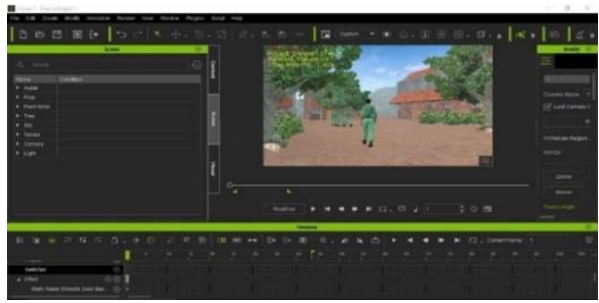

Gambar 4.7 Proses Tahapan Animation

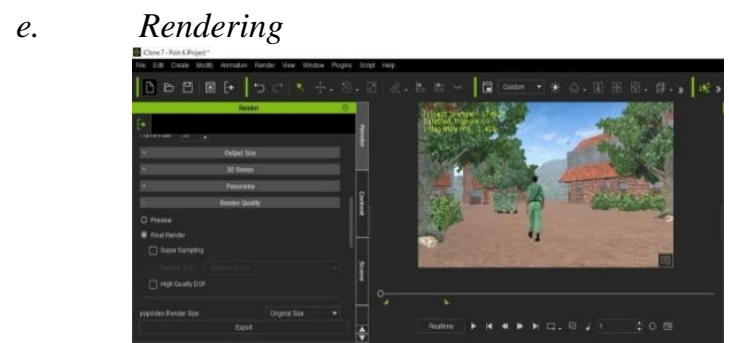

Gambar 4.8 Proses Tahapan Rendering

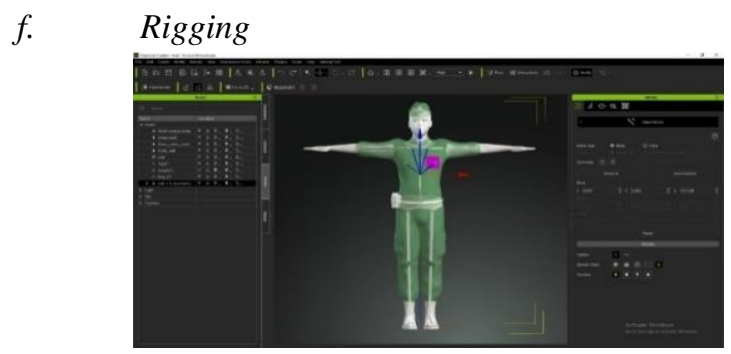

Gambar 4.9 Proses Tahapan Rigging

5. Hasil Tahapan Testing

Tahapan Testing adalah tahapan yang tidak dilakukan setelah film selesai, tetapi dilakukan sesuai dengan per scene. Film harus harus dapat berjalan secara normal di perangkar computer manapun. Jika ada kesalahan, pada scene maka akan diubah sesuai dengan revisi sesuai dengan anjuran pembimbing. Apabila berjalan sesuai dengan rancangan dan tujuan, maka proses akan memasuki tahap selanjutnya yaitu distribusi.

1. Uji Ahli Isi

Uji ahli isi digunakan untuk mengetahui standar pengukuran film animasi 3 dimensi yang meliputi informasi cerita, isi dan alur cerita, kesesuaian synopsis yang digunakan kedalam cerita sejarah Film Animasi 3 Dimensi Peran Kapten Ida Bagus Putu Japa dalam Serangan Umum kota Denpasar. Uji ahli isi ini melibatkan 2 orang ahli, memperoleh hasil:

$$
v=\frac{\sum \mathrm{s}}{\mathrm{n}(\mathrm{c}-1)}=\frac{(3,83+3,83)}{2(5-1)}=0,95
$$

Hasil diatas menunjukkan bahwa rata - rata koefisien indeks Aiken sebesar 0,95. Hal ini
Volume 10, Nomor 3,Tahun 2021

menunjukkan bahwa film animasi 3 dimensi sudah "Sangat Valid" dan layak digunakan media sosialisasi dan edukasi kepada masyarakat Kota Denpasar.[1]

2. Uji Ahli Media

Uji ahli media digunakan untuk mengetahui kesesuaian teknis pada film animasi 3 dimensi yang meliputi dalam segi visual maupun audio. Uji ahli isi ini melibatkan 2 orang ahli, memperoleh hasil:

$$
v=\frac{\sum \mathrm{s}}{\mathrm{n}(\mathrm{c}-1)}=\frac{(3,75+4)}{2(5-1)}=0,96
$$

Hasil diatas menunjukkan bahwa rata - rata koefisien indeks Aiken sebesar 0,96. Hal ini menunjukkan bahwa film animasi 3 dimensi sudah "Sangat Valid" dan layak digunakan media sosialisasi dan edukasi kepada masyarakat Kota Denpasar.[7]

3. Uji Respon Pengguna

Uji respon pengguna dilakukan untuk mengetahui kepuasan dan tanggapan masyarakat terhadap Film Animasi 3 Dimensi Peran Kapten Ida Bagus Putu Japa dalam Serangan Umum Kota Denpasar. Penyebaran ini dilakukan dengan mendatangi responden secara langsung agar lebih efisien. Setelah itu penyeberan angket dilakukan di Kota Denpasar sebanyak 50 responden. Dengan menggunakan rumus skala linkert :

$$
p=\frac{2178}{2500} x 100 \%=87 \%
$$

Dan hasil rata - rata presentase yang didapatkan dari rumus skala likert adalah $87 \%$ maka dapat disimpulkan bahwa Film Animasi 3 Dimensi Peran Kapten Ida Bagus Putu Japa dalam Serangan Umum Kota Denpasar dengan memperoleh kategori baik. Sehingga Film Animasi 3 Dimensi ini layak digunakan media sosialisasi dan edukasi kepada masyarakat Kota Denpasar.[3]

\section{B. Pembahasan}

Pengembangan Film Animasi 3 Dimensi Peran Kapten Ida Bagus Putu Japa dalam Serangan Umum Kota Denpasar dikembangkan untuk memberikan gambaran dan visualisasi kisah cerita perjuangan tokoh pahlawan Kapten Ida Bagus Putu Japa. Kapten Ida Bagus Putu Japa merupakan pahlawan yang berasal dari kota Denpasar. Ia dikenal berani melawan penjajah Belanda dalam mempertahankan kota Denpasar sampai titik darah penghabisan. Namun masih banyak masyarakat khususnya kota Denpasar yang tidak mengetahui perjuangan beliau. Oleh Karena itu, untuk memberikan informasi dan gambaran tentang Peran Kapten Ida Bagus Putu Japa dalam Serangan Umum Kota 
Denpasar, maka dikembangkan sebuah film animasi 3 dimensi yang menceritakan kisah perjuangan beliau dalam mempertahankan Kota Denpasar.

Berdasarkan Bab sebelumnya yang dapat mendukung penelitian terkait pembuatan Film Animasi 3 Dimensi Peran Kapten Ida Bagus Putu Japa dalam Serangan Umum Kota Denpasar yang pertama dari Satria Poeji Oetomo (2013) dengan judul Film Animasi Sejarah Penyobekan Bendera di Hotel Yamato bertujuan mengangkat cerita sejarah untuk sarana media pembelajaran yang baru dan lebih kounikatif serta mengasah imajinasi[6]. Penelitian kedua dari Josten V.H. Sadouw (2018) dengan judul Film Pendek Animasi 3 Dimensi Sejarah masuknya Injil di Galela bertujuan menampilkan dan menceritakan bagaimana sejarah masunya injil ditanah Galela dalam bentuk Film Pendek Animasi 3 Dimensi.[8]

Film Animasi 3 Dimensi ini menggunakan metode Multimedia Development Life Cycle versi Luther - Sutopo. metode pengembangan Multimedia Development Life Cycle terdiri dari 6 tahap, yaitu concept, design, material collecting, assembly, testing, dan distribution.[2]

Tahapan Concept merupakan tahapan paling dasar dalam pengembangan film animasi 3 dimensi. Yang dilakukan pada tahap concept ini adalah menentukan rancangan awal yang akan dibuat ke dalam film animasi. mencari sumber informasi serta pengumpulan bahan awal. Pada tahap concept hal paling mendasar dan pertama kali yang harus dilakukan adalah menentukan film animasi akan dibuat dan sasaran tujuan. Judul pengembangan Film Animasi 3 Dimensi Peran Kapten Ida Bagus Putu Japa dalam Serangan Umum Kota Denpasar, Saya memilih peran pahlawan Kapten Ida Bagus Putu Japa dikarenakan saya ingin memperkenalkan kembali pahlawan asli bali yaitu beliau karena masih banyak pahlwan-pahlawan berjasa di bali akan tetapi masih banyak yang belum terekspos di publik maka dari itu saya ingin mengangkat nama pahlawan yaitu salah satunya Kapten Ida Bagus Putu Japa.

Tahapan Design adalah tahapan perancangan sebuah karakter film animasi, rancangan karakter dimulai dari karakter utama yaitu Kapten Ida Bagus Putu Japa, Jero Wati, I Gusti Ngurah Bagus Sugianyar, I Gusti Ngurah Rai dan karakter lainnya. Pada tahapan ini tidak hanya merancang karakter tetapi juga merancang latar tempat pendukung yang akan digunakan dalam pembuatan film animasi dan juga merancang cover CD, sampul cover CD/DVD , poster Film animasi 3 dimensi Peran Kapten Ida Bagus Putu Japa dalam Serangan Umum Kota Denpasar. Untuk karakter dari tokoh utama tersebut saya mengacu dari foto beliau semasa hidupnya, oleh karena itu saya membuat inovasi untuk merancang sendiri tokoh utama tersebut dalam bentuk animasi 3 deminsi bisa dilihat padaa table 4.2 di table tersebut di perlihatkan untuk desain 2 dimensi dan 3 dimensi tokoh utama maupun tokoh pendukung, dan untuk karakter pendukung saya melihat beberapa refrensi di internet maupun di beberapa social media maka dari itu saya berinovasi membuat desain karakter pendukung tersebut sendiri.

Tahapan Material Collecting adalah tahapan pengumpulan bahan. Pada tahapan ini bahan yang diperlukan dalam pembuatan film animasi yaitu antara lain dubbing, video, audio, dan bahan lainnya yang dapat menunjang pembuatan film animasi, untuk Software yang digunakan Blender, Iclone versi 7.7, Sony Vegas, Adobe Photoshop mengapa peneliti memilih software terasebut karena peneliti lebih memahami aplikasi tersebut dari pada aplikasi-aplikasi yang lain dan lebih mudah dalam penggunaanya, dalam pemilihan dubbing itu sendiri peneliti memilih ruangan yang kedap suara untuk tempat tersebut peneliti memilih di studio radio karena salah satunya untuk menghindari noise pada saat pengambilan suara atau dubbing tersebut.

Tahapan Assembly adalah tahapan pembuatan film animasi yang berdasarkan rancangan design yang telah dibuat sebelumnya. Tahap ini dibagi menjadi dua tahap, yang pertama tahap produksi yang meliputi modeling karakter, teksturing, rigging, animating, lighting, dan rendering. Kemudian tahap pasca produksi yang meliputi editing audio dan editing video, maka dari itu peneliti menggunakan aplikasi iclone karena aplikasi tersebut mempermudah dalam pembuatan modeling karakter, teksturing, ringing, animating, lighting, dan rendering karena disana memiliki banyak fitur-fitur penunjang kebutuhan untuk pembuatan film animasi 3 dimensi tersebut, dan untuk menggabungkan audio dan hasil video render dari iclone peneliti menggunakan aplikasi sony vegas karena aplikasi tersebut juga mempermudah untuk penggabungan audio dan hasil video tersebut.

Tahapan Testing adalah tahapan pengujian film untuk mengetahui atau mengukur kelayakan film animasi 3 dimensi. Pada pengujian ini dilakukan melalui 3 tahapan pengujian yaitu uji ahli isi, uji ahli media dan uji respon pengguna. Uji ahli isi menggunakan 2 penguji yaitu bapak I Gusti Bagus Saputra, S.H yang merupakan Ketua Legiun Veteran Republik Indonesia Provinsi Bali dan bapak Ketut Suwerta., S.H merupakan Kepala Dinas Sosial Provinsi Bali. Pengujian dilakukan pada tanggal 30 Mei 2021 tahap 1 dan tanggal 8 Juni 2021 tahap 2. Pengujian ini dilakukan dengan secara langsung dan tatap muka atau offline dengan menggunakan instrument angket untuk menguji isi dari film animasi 3 dimensi. Berdasarkan hasil dari data pengujian pada uji ahli isi mendapatkan kriteria "Sangat Valid" dengan validitas Aiken sebesar 0,95 dengan beberapa saran yang telah peneliti perbaiki.

Uji ahli media menggunakan 2 penguji yang merupakan dosen Prodi Pendidikan Teknik Informatika, Jurusan Teknik Informatika, Universitas Pendidikan Ganesha atas nama bapak I Gede Partha Sindu, S.Pd., M.Pd dan bapak I Nengah Eka Mertayasa, S.Pd., M.Pd. Pengujian ahli media dilakukan pada tanggal 28 Mei 2021 tahap 1 dan tanggal 15 Juni 2021 tahap 2. Pengujian ahli media ini 
dilakukan melalui system daring atau online dengan cara mengirimkan link google drive yang berisikan file video film animasi 3 dimensi yang dishare kepada uji ahli, disertai dengan penilaian menggunakan instrument angket dalam bentuk format word atau pdf yang nantinya di isi oleh uji ahli di tempatnya masing-masing kemudian hasil dari penilaian dikirimkan kembali ke peneliti hal itu dikarenakan dengan adanya kebijakan untuk bekerja di rumah saja (Work From Home) dari pemerintah sehubungan dengan adanya masa pandemi Covid-19. Berdasarkan hasil dari data pengujian pada uji ahli isi mendapatkan kriteria "Sangat Valid" dengan validitas Aiken sebesar 0,96 dengan beberapa saran yang telah peneliti perbaiki.

Uji respon pengguna penulis menggunakan 50 responden secara acak yang merupakan masyarakat asli Kota Denpasar. Uji respon ini dilakukan dengan mendatangi responden secara langsung serta penyebaran angket kepada masyarakat pada tanggal 20 Juni 2021 sampai dengan tanggal 27 Juni 2021 dengan banyaknya soal sebesar 10 soal. Pada uji respon pengguna mendapatkan kriteria "Baik" dengan indeks validitas nilai $87 \%$ Sehingga Film Animasi 3 Dimensi ini layak digunakan media sosialisasi dan edukasi kepada masyarakat Kota Denpasar.

Tahapan Distribution adalah tahapan terakhir dari pembuatan film animasi 3 dimensi. Tahapan ini merupakan tahapa pendistribusian film animasi. Film animasi 3 dimensi ini akan distribusikan ke Legiun Veteran Republik Indonesia Provinsi Bali dan sebagai sarana media informasi kepada masyarakat kota Denpasar.

Pengembangan film animasi ini masih banyak memiliki kekurangan diantaranya informasi dan referensi tentang perjuangan Kapten Ida Bagus Putu Japa memiliki keterbatasan, peneliti menemukan hanya 2 buku saja yang membahas perjuangan Kapten Ida Bagus Putu Japa. Selain itu juga keterbatasan pada alat dalam pembuatan film animasi sangat berpengaruh dalam pembuatan film ini, dikarenakan penulis memanfaatan fasilitas seadanya yang dimiliki dirumah untuk membuat film ini sehingga film ini belum bisa dikatakan masksimal.

\section{KESIMPULAN DAN SARAN}

\section{Kesimpulan}

Adapun kesimpulan yang didapat dari tahapan Pengembangan Film Animasi 3 Dimensi Peran Kapten Ida Bagus Putu Japa dalam Serangan Umum Kota Denpasar yaitu sebagai berikut :

1. Film Animasi 3 Dimensi Peran Kapten Ida Bagus Putu Japa dalam Serangan Umum Kota Denpasar adalah sebuah film yang menceritakan perjuangan Kapten Ida Bagus Putu Japa dalam Serangan Umum Kota Denpasar serta membuktikan semangat para pejuang mengusir para penjajah Belanda. Pengembangan pada film animasi ini menggunakan beberapa software atau aplikasi, seperti Iclone dan blender untuk mendesain karakter maupun latar tempat pendukung lainnya serta menganimasikan atau gerakan pada karakter dan arah camera, Adobe Photoshop untuk membuat material atau texturing terhadap karakter dan latar tempat pendukung, Sony Vegas untuk mengedit audio dan edit video yang digunakan mengedit dubbing karakter dan juga menyambungkan video per scene. Dengan adanya Film Animasi 3 Dimensi Peran Kapten Ida Bagus Putu Japa dalam Serangan Umum Kota Denpasar diharapkan mampu memberikan gambaran dan visualisasi tentang cerita perjuangan tokoh pahlawan Kapten Ida Bagus Putu Japa dan menambah wawasan masyarakat terhadap pahlawan.

2. Berdasarkan hasil dari data pengujian pada uji ahli isi mendapatkan kriteria "Sangat Valid" dengan validitas Aiken sebesar 0,95. Pada uji ahli media mendapatkan kriteria "Sangat Valid" dengan validitas Aiken sebesar 0,96. Pada uji respon pengguna mendapatkan kriteria "Baik" dengan indeks validitas nilai $87 \%$ Sehingga Film Animasi 3 Dimensi ini layak digunakan media sosialisasi dan edukasi kepada masyarakat Kota Denpasar.

\section{Saran}

Adapun pertimbangan dalam pengembangan film animasi 3 dimensi selanjutnya adalah sebagai berikut :

1. Sumber informasi cerita perjuangan Kapten Ida Bagus Putu Japa masih sangat sedikit penulis menemukan hanya 2 buku yang membahas Kapten Ida Bagus Putu Japa dalam Serangan Umum Kota Denpasar.

2. Masih banyak sekali pahlawan pahlawan di Indonesia yang khususnya dibali ini yang masih belum terekspos di publik, maka dari itu saya sangat berharap kepada pemuda pemudi untuk membuat film ataupun animasi 3 dimensi tersebut supaya kedepannya masyarakat mengetahui bahwasanya perjuangan-perjuangan tokoh pahlawan di Indonesia ini sangat hebat tidak kalah dengan perjuangan pahlawan-pahlawan dinegara lain, dan supaya meningkatkan rasa cinta kepada Negara Republik Indonesia.

\section{REFERENSI}

[1] Arifin, Z., \& Retnawati, H. (2017). Pengembangan instrumen pengukur higher order thinking skills matematika siswa SMA kelas X. PYTHAGORAS: Jurnal Pendidikan Matematika. https://doi.org/10.21831/pg.v12i1.14058

[2] Binato, I. (2010). Multimedia Digital-Dasar Teori dan Pengembangan. 
[3] Dewi, N. D. L., \& Prasetyo, Z. K. (2016). Pengembangan instrumen penilaian IPA untuk memetakan critical thinking dan practical skill peserta didik SMP. Jurnal Inovasi Pendidikan IPA, 2(2), 213. https://doi.org/10.21831/jipi.v2i2.11963

[4] Hasan, S Hamid. 2012. "Pendidikan Sejarah untuk Memperkuat Pendidikan Karakter". Jurnal Jurusan Pendidikan Sejarah, Universitas Pendidikan Indonesia, Bandung. Paramita Vol. 22 No. 1 Januari 2012: 1 - 130

[5] Nur, H. (2005). Storyboard Dalam Pembelajaran Interaktif. Retrieved November 23, 2019, from https://doi.org/10.4135/9781452229669.n3524

[6] Oetomo, Satria Poeji. 2013. Film Animasi Sejarah Penyobekan Bendera di Hotel Yamato. Fakultas Teknik Sipil dan Perencanaan Universitas Pembangunan Nasional "Veteran" Jawa Timur. Vol. 2, No.2, Juli 2013:235-252

[7] Rahmat \& Irfan, Dedy. (2019). Rancang Bangun Media Pembelajaran Interaktif Komputer dan Jaringan Dasar di SMK. Jurnal Vokasional Teknik Elektronika dan Informatika, 7 (1), 48-53. Diakses dari:

(http://ejournal.unp.ac.id/index.php/voteknika/arti cle/view/103642/).

[8] Sadouw, Josten Van Her, dkk. 2018. "Film Pendek Animasi 3 Dimensi Sejarah Masuknya Injil di Galela”. Teknik Elektro Universitas Sam Ratulangi Manado. E-jurnal Teknik Informatika Vol 14, No.1 (2018) ISSN: 2301- 8364

[9] Wirawan, Bagus A.A,dkk. 2018. Inventaris Peristiwa dan Tokoh Sejarah. Bali: Dinas Kebudayaan Provinsi Bali 